
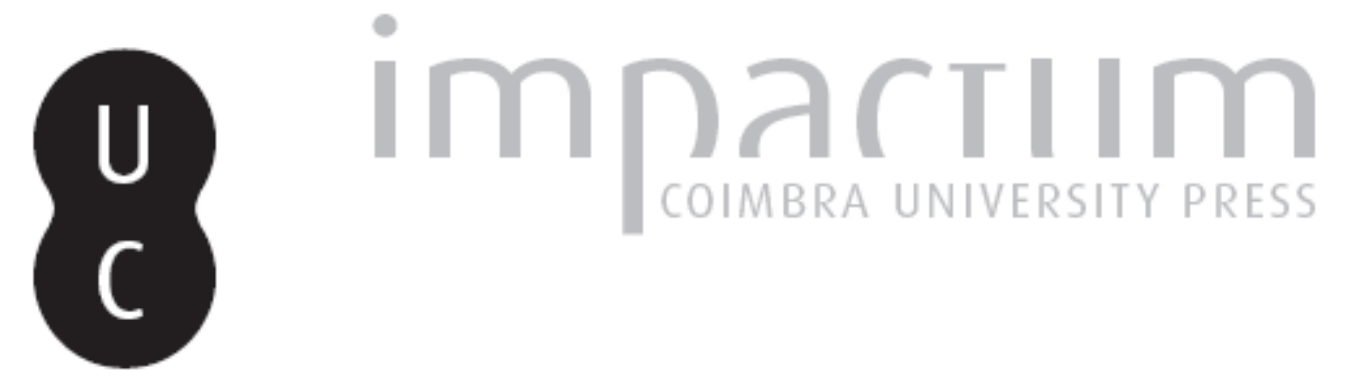

Filosofia, ciência e retórica: a viragem retórica do século $\mathrm{XX}$ aos nossos dias

Autor(es): $\quad$ Ribeiro, Henrique Jales

Publicado por: Imprensa da Universidade de Coimbra

URL persistente:

URI:http://hdl.handle.net/10316.2/42827

DOI:

DOI:http://dx.doi.org/10.14195/0872-0851_48_4

Accessed : $\quad$ 26-Apr-2023 14:07:28

A navegação consulta e descarregamento dos títulos inseridos nas Bibliotecas Digitais UC Digitalis, UC Pombalina e UC Impactum, pressupõem a aceitação plena e sem reservas dos Termos e Condições de Uso destas Bibliotecas Digitais, disponíveis em https://digitalis.uc.pt/pt-pt/termos.

Conforme exposto nos referidos Termos e Condições de Uso, o descarregamento de títulos de acesso restrito requer uma licença válida de autorização devendo o utilizador aceder ao(s) documento(s) a partir de um endereço de IP da instituição detentora da supramencionada licença.

Ao utilizador é apenas permitido o descarregamento para uso pessoal, pelo que o emprego do(s) título(s) descarregado(s) para outro fim, designadamente comercial, carece de autorização do respetivo autor ou editor da obra.

Na medida em que todas as obras da UC Digitalis se encontram protegidas pelo Código do Direito de Autor e Direitos Conexos e demais legislação aplicável, toda a cópia, parcial ou total, deste documento, nos casos em que é legalmente admitida, deverá conter ou fazer-se acompanhar por este aviso. 


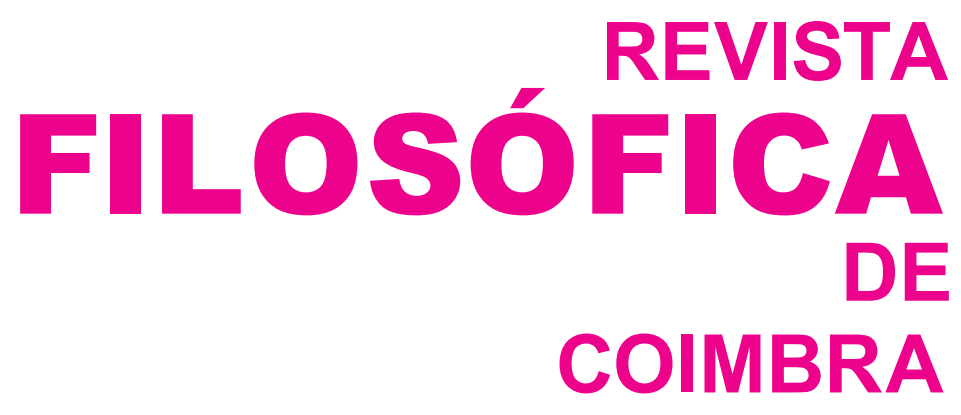

vol. 24 - número 48 - outubro 2015

vol. 24 - número 48 - outubro 2015

Fundação Eng. António de Almeida

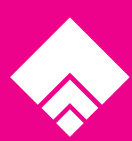




\title{
FILOSOFIA, CIÊNCIA E RETÓRICA: A VIRAGEM RETÓRICA DO SÉCULO XX AOS NOSSOS DIAS
}

\author{
HENRIQUE JALES RIBEIRO ${ }^{1}$
}

Resumo: $\mathrm{O}$ autor examina neste artigo as relações entre a abordagem da ciência feita pela filosofia e aquela que foi feita até aos nossos dias, de Perelman e Toulmin em diante, pela retórica. Com estes objetivos, as rotas do conceito contemporâneo de "filosofia da ciência" são analisadas, bem como, em especial, o suposto fim dessa filosofia e o da filosofia de maneira geral anunciado por vários autores na segunda metade do século XX (Quine, Kuhn, Feyerabend, Rorty e outros). E avança com a ideia de que, a partir dessa altura e perante um tal fracasso, ocorreu uma decisiva viragem para a retórica por parte da filosofia, como o enquadramento fundamental na perspetiva do qual devemos compreender hoje em dia a problemática desta e a da ciência em particular. Deste ponto de vista, põe em contraste a referida viragem (a viragem retórica) com a chamada "viragem linguística". Por fim, alguns dos conceitos e orientações fundamentais da retórica da ciência são atentamente estudados, colocando-se em evidência as suas profundas implicações filosóficas.

Palavras-chave: filosofia da ciência, Kuhn, retórica, Perelman, Quine, Rorty, viragem linguística, viagem retórica.

Abstract: In this paper, the author looks into the relations between philosophy's approach to science and the approach to it to the present day - from Perelman and Toulmin onwards - by rhetoric in particular. With this purpose, the paths of the contemporary concept of "philosophy of science" are closely analysed, as well as, in particular, the alleged end of that philosophy and of philosophy in general, as announced by several authors in the second half of the 20th century (Quine, Kuhn, Feyera-

\footnotetext{
${ }^{1}$ Professor associado, com agregação, do departamento de Filosofia, Comunicação e Informação da Faculdade de Letras da Universidade de Coimbra; e-mail: jalesribeiro@ gmail.com
} 
bend, Rorty and others). The author submits further the idea that, from that time and in face of such failure, philosophy turned decisively to rhetoric, as the fundamental framework for understanding today philosophical problems and the problems of science in particular. From that point of view, he compares this turn (the rhetorical turn) with the so-called "linguistic turn". Finally, some of the fundamental concepts and guidelines of the rhetoric of science are studied closely, hereby highlighting its profound philosophical implications.

Keywords: Kuhn, linguistic turn, philosophy of science, Perelman, Quine, rhetoric, rhetorical turn, Rorty.

\section{Introdução}

Neste trabalho procura-se analisar as relações entre filosofia da ciência e retórica da segunda metade do século XX aos nossos dias, e, em particular, que consequências é que teve para essa filosofia e a filosofia de modo geral aquilo a que podemos chamar a "viragem retórica" feita pelos trabalhos de Perelman \& Olbrechts-Tyteca (1958/2008) e de Toulmin (1958/2008). A expressão "viragem retórica" não é tão corrente como outras mais ou menos análogas ("viragem linguística" por exemplo [cf. Rorty 1967/1992]), mas, como veremos, é apropriada e faz todo o sentido. A ideia central é que a viragem a que aludimos constituiu simultaneamente o fim ou o colapso da filosofia da ciência tradicional: a retórica passa, a partir dos trabalhos referidos, a ocupar em novos temos o papel que era atribuído, anteriormente, a uma tal filosofia e a apresentar-se como o verdadeiro paradigma de racionalidade. Explicar como é que esta transformação fundamental ocorreu, investigar e elucidar as razões que estão na sua origem - são os nossos objetivos principais.

Num primeiro momento, vamos procurar analisar e caracterizar o conceito ele mesmo de "filosofia da ciência". A sua significação histórica e filosófica está longe, hoje em dia, de ser evidente ou inofensiva - muito pelo contrário. De seguida, mostra-se que no próprio âmbito dessa filosofia - e mais ou menos na mesma altura em que se dá a viragem retórica e a emergência da retórica como paradigma de racionalidade - se concluiu pela sua ilegitimidade e inutilidade. O "fim da filosofia da ciência", como lhe chamámos noutro lado (Ribeiro 1998), começa por ser anunciado pelos próprios filósofos da ciência, independentemente, de algum modo, da viragem em causa. Faz parte do que se designa, de maneira corrente, por "pós-modernidade" (cf. Lyotard 1979); e tem contornos que, deste ponto de vista, importa esclarecer.

Num segundo momento, essa viragem é atentamente explicada, e as suas implicações e consequências para a filosofia no seu conjunto serão postas 
em destaque. Ver-se-á que a emergência da retórica como paradigma de racionalidade constitui uma mudança decisiva e revolucionária para o destino da filosofia ocidental da Grécia clássica aos nossos dias. Essa mudança não abrange apenas a filosofia da ciência mas engloba, de facto, todos os outros campos do conhecimento e da ação humana, aí incluindo, numa perspetiva filosófica, para além da metafísica e da epistemologia, da ética e da estética, a lógica por exemplo (cf. Ribeiro 2012a). Do que se trata, na verdade, é de respostas completamente novas às questões que Kant tinha formulado com as suas Críticas, e particularmente com as duas primeiras (a da razão pura e a da razão prática): "o que é que posso conhecer ?", "o que é que devo fazer ?" Seja como for, a amplitude da significação da revolução a que acabamos de aludir está por compreender e estudar em grande parte; o que acontece é que ainda estamos a vivê-la em profundidade, envolvidos na sua densa e complexa problemática.

Concluindo e à luz do que se acaba de dizer, faz-se o esboço de alguns dos problemas com os quais somos confrontados, hoje em dia, na nossa abordagem retórica da ciência, e das tarefas que temos pela frente.

\section{Sobre as rotas do conceito de filosofia da ciência}

O conceito de filosofia da ciência tem uma matriz tipicamente cartesianokantiana, que caracteriza a modernidade filosófica no seu conjunto. A ideia, que Descartes desenvolve, metafisicamente falando, no Discurso do Método e (em especial) nas Meditações, e Kant - independentemente desse tipo de pressupostos - na Crítica da Razão Pura, é que compete essencialmente à filosofia justificar a possibilidade do conhecimento científico, i.é, da matemática e da física, como o enquadramento fundamental do conhecimento humano de maneira geral. É de um tal enquadramento que Kant se serve nessa obra, utilizando para o efeito, como é sabido, a geometria euclidiana e a conceção da mecânica de Newton (cf. Kant 1787/1985, pp. 15-39). A ciência, nesta perspetiva e em contraste com a interpretação que virá a ser feita posteriormente pelo idealismo absoluto alemão (Fichte, Schelling e Hegel), é um objeto exterior à filosofia, quer dizer, não se identifica necessariamente com esta. O papel da filosofia, como "ciência primeira" deste ou daquele modo entendida, é precisamente o de analisar os "princípios" ou conceitos que estão na base dos axiomas da geometria e das leis da física, para, por essa via, mostrar como é que o homem pode vir a conhecer o que quer que seja. É irrelevante para a definição e estudo do conceito de "filosofia da ciência" até aos nossos dias, que quer o que se entende por matemática quer o que se entende por física, mude de forma significativa. No início do século XX a 
geometria euclidiana deixa de ser paradigma da matemática, com o aparecimento das não-euclidianas e outros desenvolvimentos; e a física de Newton, por sua vez, é relegada para um plano secundário com o surgimento da teoria da relatividade. O essencial consiste nesse papel justificatório por parte da filosofia, a que aludimos. E deste ponto de vista, como mostrámos noutros lados (Ribeiro 2004, 2005, 2007) mas veremos atentamente mais à frente, filosofias da ciência como as de Popper e do positivismo lógico, são caracteristicamente kantianas, mesmo quando - como é o caso das do segundo - se opõem por vezes de forma expressa às teorias de Kant e da Crítica da Razão Pura em particular (por exemplo, às teorias desse filósofo sobre a geometria). Há, em tudo aquilo que acabamos de dizer, vários aspetos que importa analisar atentamente.

Que a ciência (física e matemática) seja um objeto exterior à filosofia, ou que a filosofia não se identifique completamente com ela, significa que o filósofo não faz necessariamente ciência no âmbito da sua própria filosofia da ciência, qualquer que ela seja. O idealismo absoluto alemão, como se sabe, desenvolveu uma conceção diferente: o filósofo pode ele mesmo fazer ciência com esta ou aquela Wissenschaftstheorie. As Ideias para uma Filosofia da Natureza, de Schelling, ou a Filosofia da Natureza de Hegel, constituem um exemplo notável disso mesmo. Retomam a velha ideia - que provém remotamente de Aristóteles -, de que todas as ciências nasceram da filosofia como ciência primeira, e a que Descartes não deixará de apelar, nos Princípios da Filosofia, concebendo a filosofia (a metafísica em particular) como o tronco de uma árvore cujos ramos são os diferentes saberes científicos (cf. Descartes 1644/1985). Mas o idealismo absoluto alemão, com exceção de alguns desenvolvimentos episódicos e residuais por parte das escolas neo-hegelianas dos finais do século XIX, não teve um impacto significativo na história da filosofia (cf. Ribeiro 2013a). A distinção cartesiano-kantiana entre os dois campos, por outro lado, possibilitava a necessária autonomia à investigação estritamente científica, se bem que, teoreticamente, a justificação dessa investigação passasse em última análise pela filosofia. E essa autonomia, lá para o início do século XX, saía reforçada pela autonomia propriamente institucional do ensino e investigação em física teórica e experimental que se começou a verificar nas universidades europeias de maneira geral. À filosofia compete justificar e/ou fundamentar, como na Crítica da Razão Pura se defende, quer dizer, oferecer razões mais ou menos últimas para a explicação científica propriamente dita. Em todo o caso, como é que o filósofo pode desenvolver uma tal tarefa sem, de certo modo, estar já a "fazer ciência" e cair nas malhas do hegelianismo? A resposta, mais uma vez, tem a ver com Kant, e com aquilo a que o filósofo de Königsberg chamava "analogias da experiência" (Kant 1787/1985: pp. 208 e ss.). A filosofia, por forma 
a cumprir o seu papel, é obrigada a reconstruir figurativa e analogicamente no seu próprio âmbito a experiência científica supostamente em curso ela mesma. É o que Nagel (1961/1974, pp. 109 e ss.) virá a sustentar tendo em vista a filosofia da ciência propriamente contemporânea.

Porque é que a matemática e a física são consideradas como o enquadramento científico fundamental da filosofia da ciência ? Na verdade, isso aconteceu desde Descartes e Kant até ao fim dessa filosofia propriamente dita, com Kuhn (1962/2012) e com Quine (1953/1994, 1969) particularmente. Porque é que - diremos nós agora, depois do aparecimento e desenvolvimento das ciências humanas no último quartel do século XIX - não poderão ser quaisquer outras? A resposta é que a matemática e a física, por sua vez, são o enquadramento do conhecimento humano de maneira geral e do da natureza em particular. Trata-se de um pressuposto epistemológico que remonta aos dois grandes filósofos que marcam decisivamente a época moderna, e que foi subscrito não só por Popper mas também pelas várias versões do positivismo lógico. É ele que está na base - dos anos trinta do século passado em diante - das teorias fisicalistas e da ideia de uma "enciclopédia das ciências unificadas". Como já se sugeriu, é um pressuposto problemático e discutível. O problema, vê-lo-emos, não consiste tanto em defender que sejam o enquadramento do nosso conhecimento da natureza, mas que um tal enquadramento constitua o paradigma do conhecimento humano no seu conjunto.

O ponto decisivo do desacordo entre as principais filosofias da ciência durante o século XX e Kant, desde os logicismos de Frege e (particularmente) de Russell, é sem dúvida, a crítica do (suposto) psicologismo das teorias desse filósofo. Como se sugerirá mais à frente, a única exceção nesta matéria -é oferecida por Popper (1959/1974), que nunca renegou o seu kantismo (cf. Popper 1963/1991, pp. 175-183; Popper 1976). O cerne dessa crítica é que uma justificação como aquela que Kant apresentou para a geometria euclidiana não podia mais ser aceite face ao que as geometrias não-euclidianas, em qualquer das suas versões, vinham recentemente mostrar: que o papel do sujeito e daquilo a que esse filósofo chama "axiomas da intuição" (Kant 1787/1985, pp. 198 e ss.) é completamente irrelevante. Em consequência e mais decisivamente, deixa de ser relevante todo o aparelho cognitivo que Kant tinha concebido para explicar a possibilidade do conhecimento científico e do conhecimento de maneira geral, em particular: formas $a$ priori do espaço e do tempo, conceitos puros ou categorias do entendimento (cf. Ribeiro 2004, 2005). Russell (1903/1992), com uma postura triunfadora, começou por fazer estas objeções logo no começo do século e o positivismo lógico, desde a sua fase vienense, irá repeti-las à exaustão. Este é, de resto, o grande motivo que levou os principais protagonistas desse movimento, 
como Schlick e Carnap, a abraçar o convencionalismo. A contra-objeção, numa perspetiva neokantiana, está em sustentar que não é de forma alguma essencial ao kantismo uma interpretação psicologista das formas e conceitos a que nos referimos antes; são apenas condições meta-filosóficas da ciência e do conhecimento, como, de resto, começa por sê-lo o próprio conceito de razão pura, que é basicamente um conceito ideal e regulativo. E. Cassirer e as escolas neokantianas do princípio do século, como se sabe, desenvolveram atentamente esta interpretação (cf. Cassirer 1907; Friedman \& Nordmann 2006). Por outro lado, como mostrou Friedman $(1992,1999)$, o que as filosofias da ciência positivistas acabam por fazer, finalmente, é substituir essas condições meta-filosóficas por outras, entre as quais precisamente a interpretação convencionalista da ciência como um sistema axiomático-dedutivo. $\mathrm{O}$ essencial, como vimos até aqui, parece não se ter alterado e é kantiano: a ideia de que a filosofia constitui um empreendimento fundador último sobre a ciência; e de que, portanto, um tal empreendimento não só é legítimo mas faz todo o sentido. É essa ideia que vai entrar em crise com a crítica ao positivismo lógico feita por Kuhn (1962/2012), Quine (1953/1994, 1969) e outros autores, dos anos sessenta em diante, e que conduz ao fim da filosofia da ciência celebrado por Feyerabend $(1987,1999)$ e à pós-modernidade de maneira geral, onde ainda nos encontramos.

\subsection{O fim da filosofia da ciência}

A ideia de que a filosofia da ciência- no sentido fundacionalista que foi analisado na secção anterior deste trabalho - morreu ou chegou ao fim foi defendida recorrentemente na segunda metade do século XX, por autores tão diversos como Kuhn, Quine, Feyerabend e Rorty. (Não, é verdade, por autores como Popper [1994], que não deixará de desempenhar, como mostrámos noutro lado [Ribeiro 2015b] um papel fundamental na viragem retórica e nas conceções contemporâneas do pensamento crítico.) E isso aconteceu, como se disse na introdução, mais ou menos ao mesmo tempo da viragem retórica, com os trabalhos de Perelman \& Olbrechts-Tyteca (1958/2008) e de Toulmin (1958). Mais à frente argumentaremos que este paralelismo não é irrelevante, e que o fim - pública e reiteradamente anunciado - da filosofia da ciência foi a alavanca principal da viragem retórica. Em rigor, não se defende que toda a filosofia da ciência tenha colapsado, porque - como é o caso de Quine $(1969,1975,1995)$ - se admitiu que versões fracas ou "naturalizadas" dessa filosofia pudessem ocupar em novos termos, em parte pelo menos, o papel da mesma. O que se rejeitou foi a tese de que a filosofia constitui deste ou daquele modo, mas através da lógica em particular - o enquadramento universal para explicar, justificar e fundar a ciência, e, em particular, a 
matemática e a física, como o positivismo lógico - nas suas versões vienense e americana, através de Carnap sobretudo - tinha defendido (cf. Carnap 1966/1973, 1975). A crítica a esta tese tem várias vertentes porque o ataque à conceção fundacionalista da filosofia da ciência ocorreu, por sua vez, em várias frentes: com a contestação do papel que a ideia cartesiano-kantiana de método da ciência tinha ocupado anteriormente até ao positivismo e a Popper (Feyerabend); com a substituição do enquadramento filosófico pelo enquadramento histórico e sociológico (Kuhn); e, como fio condutor de tudo o que acabámos de dizer, com a entrada em cena da problemática do holismo em filosofia (Kuhn, Quine, Feyerabend, Rorty), que teve consequências profundamente devastadoras para essa conceção a que aludimos (e que, por isso, é o fator fundamental que importa analisar por agora).

Os pontos essenciais que caracterizam a problemática do holismo poderiam ser apresentado nestes termos: $(\alpha)$ não existe, como referência do nosso conhecimento do mundo e seja qual for o campo do mesmo (como é o caso das teorias da física), um dado virgem e imune às interpretações que dele fazemos através das nossas teorias; esse (suposto) dado está sempre, de uma forma ou de outra, impregnado pela teoria ou teorias com que o interpretamos, quer dizer, varia essencialmente com esta(s); $(\beta)$ por outro lado, se só existe dado à luz de uma teoria qualquer, e ele se altera ou muda, portanto, de acordo com a teoria através do qual o interpretamos, conclui-se que, finalmente, a referência ao dado é inescrutável, quer dizer, que não é possível determiná-la. A tese $(\alpha)$ coincide com a chamada "theory-ladenness of observation", cujas rotas filosóficas, em certa medida, remontam surpreendentemente ao próprio Kant e à Crítica da Razão Pura em particular; embora, como é conhecido, através da distinção entre fenómeno e númeno esse filósofo subscrevesse a ideia de que sim, existem "coisas em si" ou dados imunes às nossas interpretações. Mas, uma vez projetada na filosofia da segunda metade do século $\mathrm{XX}$, e lida à luz da $(\beta)$, essa tese está na origem do relativismo (por exemplo, de um relativismo como o de Rorty) e da ideia de que todo o nosso conhecimento do mundo é contextual, ou de que as nossas interpretações variam de contexto a contexto, e de que não temos meios para aferir completamente da respetiva validade, e em especial da validade de interpretações em conflito no mesmo contexto (cf Rorty 1991). Quine (1969), desenvolvendo e aprofundando as consequências das suas conceções em Quine (1953/1994), designou a tese $(\alpha)$ por "indeterminação da tradução" e a tese $(\beta)$ por "indeterminação da referência". No conjunto, as duas teses conduzem-no, no primeiro trabalho, não só à ideia de que toda a ontologia é relativa ao respetivo enquadramento teórico, mas, fundamentalmente, à ideia de que a significação ela mesma é um mito (cf. Quine 1962), e de que, portanto, a epistemologia (ou filosofia da ciência) tradicional, não é mais 
apropriada como abordagem filosófica da ciência. Como mostra o posfácio de Kuhn à obra A Estrutura das Revoluções Cientificas, esse autor - quando bem entendido - acaba por subscrever no livro referido, do seu próprio ponto de vista, as teses de Quine (cf. Kuhn 1962/2012, pp. 173 e ss.). Notese que não é apenas a epistemologia fundacionalista que é completamente desacreditada e chega ao seu fim, mas a própria filosofia ocidental ela mesma no seu todo, pelo menos na forma que lhe foi dada de Descartes e de Kant em diante. Por uma outra via, que não é possível analisar e desenvolver aqui, Wittgenstein (1953) chega aos mesmos resultados que Quine.

Na secção seguinte deste trabalho, teremos oportunidade de ver atentamente a leitura e interpretação que alguns dos protagonistas da "viragem retórica", como Perelman, fizeram das conceções de Quine, porque essa leitura e interpretação - que é frequentemente ignorada pela literatura especializada (uma exceção é Ribeiro 2012c) - foi um facto. Um aspeto essencial é que elas deslocavam o cerne da abordagem filosófica da ciência para o próprio discurso a seu respeito, quer dizer, para a forma como nós falamos do mundo; e que essa forma é fundamental para perceber o que quer que seja a respeito do mundo (cf. Ribeiro 2012a). Mas, por agora, importa desde já observar que a consequência principal dessas conceções consistiu em mandar para a prateleira a filosofia da ciência do positivismo lógico no seu todo, e, em particular, aquilo a que Quine (1953/1994, pp. 20-46) chamou os "dogmas" da "analiticidade" e do "verificacionismo". No âmbito deste último, e à revelia do holismo e suas consequências, presumia-se que era possível verificar ou corroborar empiricamente uma dada teoria da física, axiomatizada deste ou daquele modo com os recursos da lógica, e de que, portanto, existiria aquele dado puro e imune às nossas interpretações que o holismo precisamente vinha pôr em causa. (Pelas mesmas razões poderia dizer-se que também o falsificacionismo de Popper [1959/1974] era descartado). No âmbito do primeiro, por outro lado, a presunção era - mais uma vez à revelia do holismo - que as convenções da lógica nos permitiriam por si só - ou independentemente da sua aplicação ao mundo da experiência definir os termos e conceitos fundamentais de uma teoria da física qualquer; e de que, portanto, existiria, por sua vez, uma "teoria" que não estivesse ela própria, à partida, já essencialmente impregnada por esse mundo. Nos dois casos, como Quine admite de passagem, regressa-se à distinção kantiana entre o analítico e o sintético, sem resolver a dicotomia metafísica que lhe está subjacente (cf Quine 1953/1994, pp. 20 e ss.) Em certa medida, o que Quine - do ponto de vista epistemológico - veio mostrar, no conjunto, contra Kant e os seus seguidores (declarados ou não), e que terá um impacto enorme para a viragem retórica, é que a ideia de que física e a matemática constituem um conhecimento apodítico, i.é, universal e necessário, não faz mais sentido 
e deve ser completamente descartada. Em última análise, numa perspetiva como a sua, todo o conhecimento humano releva do campo do "razoável", não do "racional". Mas Quine, como é sabido, parece ter ignorado ao longo da sua vasta obra o papel da retórica de maneira geral, e de uma retórica da ciência em particular. Isso não impediu, contudo, que os autores da viragem retórica (como Perelman) o tivessem lido desse ponto de vista.

\section{A viragem retórica e a retórica da ciência}

Chamarei "viragem retórica", por analogia com a conhecida "viragem linguística" ("linguistic turn") anunciada por Rorty (1967/1992), a transformação fundamental - operada essencialmente por Perelman \& OlbrechtsTyteca (1958/2008) e por Toulmin (1958), mas logo seguida por outros autores, correntes e escolas - que consiste em eleger como cerne da investigação filosófica de maneira geral a retórica e a argumentação. Com isso quero dizer que, no âmbito da viragem retórica, as problemáticas tradicionais, de maneira geral, da filosofia - como aquelas que dizem respeito à metafísica, à teoria do conhecimento ou epistemologia, à ética, à lógica formal, ou, como é o caso de que nos ocupamos neste trabalho, à filosofia da ciência - passam a ser encaradas essencialmente como problemáticas da retórica e argumentação. Deste ponto de vista muito geral, a minha aceção do conceito de "viragem retórica" difere desde logo substancialmente das de outros autores, que se detêm basicamente sobre aspetos parciais, não sistemáticos e sem implicações filosóficas deste ponto de vista, da mesma (cf. Simons 1990).

O ponto essencial da nossa interpretação (que desenvolvemos amplamente noutros lados [Ribeiro 2009, 2012a, 2012b]) é que a retórica e a argumentação passam a constituir a perspetiva unificadora fundamental dos diferentes campos filosóficos interdisciplinares; e aparecem, de facto, como o novo paradigma de racionalidade da era contemporânea. Com a viragem retórica, a retórica e a argumentação ocupam, em novos termos, o papel fundador do conhecimento e da ação humana de maneira geral que era anteriormente atribuído à filosofia - particularmente desde Descartes e de Kant. Aquele estatuto fundacional que Descartes atribuía à filosofia (metafísica) como tronco de uma árvore cujos ramos são os diversos saberes científicos, é agora atribuído - com Perelman e com Toulmin, e a partir deles - à retórica e argumentação elas mesmas, de uma forma que procuraremos explicar ao longo desta secção. Noutro lado, mais especificamente e tendo em vista o estudo dos seus desenvolvimentos mais recentes, identificámos essa viragem com o próprio nascimento da teoria da argumentação enquanto tal (Ribeiro 2012a). Tratase de uma autêntica revolução em filosofia (embora silenciosa, i.é, não tão 
conhecida e investigada como outras), cujas implicações e consequências ainda estão em curso, e por explicar e analisar completamente. A interpretação antiga e tradicional da retórica e da argumentação como campos secundários da filosofia ou dos estudos literários - e que perdurava ainda no tempo em que Perelman escreveu A Nova Retórica: Um Tratado sobre a Argumentação - é completamente destronada. Por outro lado, os preconceitos filosóficos conhecidos - desde Platão - a respeito da importância desses campos, o velho conflito entre retórica e filosofia (cf. Nauser 2007), deixam de fazer sentido.

\subsection{A viragem retórica e a viragem linguística}

A analogia com a "viragem linguística" de Rorty (1967/1992) é pertinente para os nossos propósitos. O que esta última viragem - especialmente quando esse autor é lido à luz de trabalhos posteriores, como Rorty (1979) significa fundamentalmente consiste em pôr a (filosofia da) linguagem - e a teoria da significação ("theory of meaning") em particular - como o cerne da atividade filosófica de maneira geral; todos os problemas filosóficos são - como o Wittgenstein do Tractatus tinha antecipado, a "English ordinary language philosophy" (Ryle, Austin, Pears, e outros autores) ilustrará, e o Wittgenstein das Investigações Filosóficas tornará patente - problemas de linguagem, no sentido em que podem ser explicados através do nosso uso da mesma nos diferentes contextos em que esse uso tem lugar, e da forma como a significação (o sentido ou a falta dele) aí ocorre. Este é, como se sabe, um axioma da chamada "filosofia analítica". Ao abrigo dele, os problemas das diferentes áreas da filosofia - e não apenas os da metafísica propriamente dita - são todos eles, de uma forma ou de outra, problemas de linguagem. Mas não só dessas áreas: como a filosofia de Wittgenstein desde o Tractatus (Wittgenstein 1921/1933) mostrou e outras - como a de Quine - exemplificarão mais claramente talvez, o mesmo poderia ser dito a respeito da matemática e das ciências de maneira geral. Poderíamos dizer que com a "viragem linguística" a filosofia da linguagem aparece de certa maneira como um paradigma da racionalidade (possível). Os desenvolvimentos desta ideia não nos interessam aqui particularmente, embora, a seguir, não deixemos de aludir a alguns deles. O ponto essencial, que importa destacar, é que a "viragem linguística" - e a filosofia analítica no seu conjunto- passa ao lado completamente das problemáticas da retórica e da argumentação; de certa maneira, ignoram-na ostensivamente (cf. Ribeiro 2012b). Como mostrámos noutros lados, a propósito da relação entre Perelman e a filosofia analítica (Ribeiro 2012c) e da relação entre Toulmin e Wittgenstein (Ribeiro 2012d), a significação no uso da linguagem para os filósofos analíticos de 
maneira geral - desde Frege, Russell e Wittgenstein até aos nossos dias não implica de forma alguma argumentação; e, por isso, o termo e conceito "argumentação", ou os seus congéneres ("retórica"), raramente são usados ou mencionados na literatura analítica. Isto é de certa forma surpreendente, senão paradoxal, porque quer a argumentação quer a retórica propriamente dita são características essenciais e irredutíveis do uso da linguagem. Como a viragem retórica veio mostrar - desde logo, com Perelman e com Toulmin - não há significação à revelia ou independentemente do uso argumentativo da linguagem.

Um ponto essencial para compreendermos a originalidade da viragem retórica face à viragem linguística, é que, mais ou menos ao mesmo tempo que Perelman \& Olbrechts-Tyteca (1958/2008) e Toulmin (1958), no âmbito da primeira viragem, ofereciam uma conceção otimista para o futuro da filosofia ao abrigo da mesma, alguns autores fundamentais da segunda - como é o caso de Wittgenstein (1953) e de Quine (1953/1974, 1969) - concluíam finalmente que a filosofia como empreendimento teorético sistemático era impossível. (Coffa [1995] escreverá um extenso livro sobre este falhanço colossal da tradição analítica em filosofia, que, para esse autor, ocorrerá logo no final dos anos trinta com o positivismo lógico vienense.) Como dirá Quine - e Wittgenstein não dirá outra coisa - o objeto por excelência da filosofia analítica - a significação - é um mito (Quine 1962). O que resta portanto à filosofia como tarefa - depois deste certificado de óbito - é a atividade da crítica e clarificação dos usos da linguagem (Wittgenstein), ou da colaboração com a ciência no âmbito de uma epistemologia naturalizada (Quine), isto é, exercícios secundários e - para todos os efeitos - sem qualquer horizonte sistemático. Os filósofos analíticos não compreenderam que era possível continuar a abraçar uma boa parte das metas da viragem linguística, depois do certificado a que aludimos, através da viragem retórica. Foi o que Toulmin, que foi aluno de Wittgenstein e um seu fiel admirador durante toda a sua vida, defendeu que esse grande filósofo estava essencialmente a sugerir com os seus últimos trabalhos (cf. Ribeiro 2012d).

\subsection{A viragem retórica e a lógica formal}

Uma das implicações que a viragem retórica trouxe foi que a própria lógica formal, isto é, aquela mesma lógica cujas fundações foram lançadas por Frege e por Russell, e desenvolvidas por autores como Tarski, Carnap, Quine e outros até praticamente aos anos sessenta do século passado (cf. Bochenski 1961), poderia constituir ela própria uma campo da retórica e da argumentação, ou daquilo a que se referem frequentemente os autores dessa viragem como "uma lógica alargada" (Perelman \& Olbrechts-Tyteca 
1958/2008, p. 10) ou uma "lógica a trabalhar" ("working logic") (Toulmin, 1958, cap. 4). O pressuposto fundamental destes conceitos é que enquanto a retórica e a argumentação constituem, de certo modo, uma lógica informal dos campos de que se ocupam naturalmente de acordo com a tradição e que dizem respeito ao uso da linguagem em contexto, esta mesma lógica pode ser alargada ou ampliada, por forma a incluir a própria lógica formal, como uma investigação sistemática sobre a argumentação no seu conjunto. Na verdade, na própria lógica formal se argumenta (a sintaxe da lógica proposicional é um exemplo disso mesmo), e certas aplicações da lógica (vê-lo-emos mais à frente), como é o caso daquelas que dizem respeito à formalização dos sistemas axiomático-dedutivos, podem ser interpretadas retoricamente (Perelman \& Olbrechts-Tyteca 1958/2008). Na há, pois, nenhuma oposição ou conflito inultrapassável entre retórica, por um lado, e lógica, por outro, como por vezes erradamente se defende a propósito dos autores da viragem retórica, e da distinção que foi feita por alguns deles entre os campos do "racional" (i.é, do apodítico, necessário e universal, que serão propriedades da lógica) e do "razoável" (i.é, do provável, verosímel, contingente, que serão propriedades da retórica) (cf. Ribeiro 2009, 2015). De resto, mais acima já se teve oportunidade de se ver que, para alguns dos mais importante lógicos do século XX, como é o caso de Quine, a lógica ela mesma, finalmente, não pertence ao campo do universal e necessário (na aceção de Kant destes conceitos). Esta inclusão da lógica formal entre os campos interdisciplinares da retórica e da argumentação faz todo o sentido depois daquilo que dissemos anteriormente quando sustentámos a tese de que elas aparecem, ao abrigo da viragem retórica, como um novo e revolucionário paradigma de racionalidade a partir da segunda metade do século XX.

$\mathrm{Na}$ verdade, antes da viragem retórica, para alguns filósofos analíticos cuja formação era essencialmente a da lógica, como é o caso de Carnap e de Quine, era a própria lógica que - com base na teoria da significação - constituía um tal paradigma. Para se comprovar este associação da lógica, que analisámos noutro lado extensamente (Ribeiro 2012a), basta reler um dos principais manuais dos anos sessenta em diante até aos nossos dias, Introdução à Lógica (Copi 1953/1994). Aí a lógica aparece não só como uma teoria dos usos da linguagem e da argumentação em particular, mas também como uma teoria das falácias, da definição, da dedução e indução, dos silogismos categóricos e hipotéticos, da lógica simbólica propriamente dita, da hipótese em ciência, da probabilidade, da lei, etc. O lógico de que estamos a falar (Quine, por exemplo) assume em relação à filosofia de maneira geral em novos termos, aquele mesmo papel de que se ocupava Hegel na sua famosa obra Ciência da Lógica (Wissenschaft der Logic [Hegel 1812-1972]), com a diferença, evidentemente, de que agora se trata de lógica matemática e não 
de metafísica. Não se esqueça, porém, que esse lógico - como mostrámos acima - é o mesmo que anunciou o fim da filosofia tal como ela foi concebida de Descartes e Kant até à época contemporânea, e assumiu e explicou longamente (Quine 1969) o falhanço da lógica em particular a esse respeito. Que agora a retórica e argumentação, pois, se assumam, filosoficamente falando, como um novo paradigma de racionalidade, mas um paradigma otimista, suscetível de desenvolvimento sistemático, é um facto de importância absolutamente decisiva.

\subsection{A retórica da ciência}

É no amplo contexto que temos vindo a analisar que deve ser compreendida a viragem retórica protagonizada, desde logo, por Perelman \& Olbrechts-Tyteca (1958/2008) e por Toulmin (1958). Em particular, essa viragem só pode verdadeiramente ser entendida à luz do fracasso da tradição filosófica - aí incluindo a própria filosofia analítica - e do da lógica em particular, em fundar aquilo que é suposto constituir o conhecimento científico. Como vimos, o contraste entre a viragem linguística e a viragem retórica é esclarecedor a este respeito. Ambas elegem a linguagem como cerne da investigação filosófica e compartilham, pois, de uma mesma matriz fundamental, que tem vários pressupostos; mas enquanto a primeira põe a teoria da significação como fio condutor e finalmente é levada a concluir que ela não é possível como empreendimento sistemático, a segunda vê na argumentação a única via de responder aos problemas essenciais dessa teoria e da filosofia de maneira geral, reformulando completa e decisivamente - numa perspetiva otimista - as tarefas e objetivos desta.

Entre os pressupostos das duas viragens, a que aludi, está a problemática do holismo. Para os autores da viragem retórica, a começar, desde logo, por Perelman, todo o uso da linguagem é feito essencialmente em contexto (como Wittgenstein e a filosofia analítica sustentavam na mesma época), e de tal modo que as partes intervenientes (orador-autor/auditório) não podem ser consideradas independente ou isoladamente uma da outra: o auditório é uma "construção" do orador/autor, quer dizer, um "dado" permeado pela teoria ou interpretação que este faz daquele à partida. Em A Nova Retórica, onde Wittgenstein é ocasionalmente referido, defende-se que esta conceção se aplica à significação de modo geral (cf. Perelman 1958/2008, pp. 120 e ss.). Não há, pois, um dado puro, virgem ou imune em relação à interpretação que dele se faz ao abrigo desta ou daquela teoria (qualquer que seja a sua versão). Perelman, logo em 1958, estende esta conceção à filosofia da ciência do seu tempo, e particularmente ao positivismo lógico, para contestar aquele mesmo dogma que Quine, três anos antes, tinha criticado em "Dois dogmas do 
empirismo": a ideia de que um tal dado existirá, e de que é possível verificá-lo ou corroborá-lo, não faz qualquer sentido, porque esse dado pura e simplesmente não existe (cf. Perelman 1989, pp. 109 e ss.). Toulmin (1958, pp. 11 e ss.) com um outro enquadramento retórico, desenvolverá a mesma perspetiva através da noção de "argumento dependente de campo"; Popper (1994, pp. 33-64) delimitá-la-á escrupulosamente, tendo em vista, por contraste, as implicações que o relativismo estava a tirar dela; e Kuhn (1962/2012), à margem da retórica propriamente dita, aplicá-la-á à história da ciência e das revoluções científicas em particular, através da noção de "paradigma", pondo decisivamente em questão algumas das suas consequências fundamentais, como as de "continuidade" e "progresso" da investigação científica (cf. pp. 159 e ss.). Em termos kantianos, todo o nosso conhecimento da natureza é fenomenal e não existe qualquer "coisa em si" (ou númeno) como suporte ontológico do mesmo; não há, em consequência, nenhuma "síntese a priori" como desiderato da filosofia. A ideia da suposta objetividade da física e das ciências físiconaturais de modo geral, é um mito, eventualmente - como o próprio Quine tinha defendido no artigo referido - uma ficção útil (Quine 1953/1994, pp. 42 e ss.), o que significa que não se podem explicar e justificar essas ciências - como Kant tinha defendido na Crítica da Razão Pura - à luz da conceção de que elas constituirão um conhecimento apodítico, universal e necessário. A ciência, não menos do que a retórica e a argumentação na vida quotidiana, pertence essencialmente ao domínio do "razoável", não do "racional". Parte de premissas filosóficas que podem ou não ser aceites à partida pelos cientistas ou por esta ou aquela comunidade científica, e que são matéria de um acordo possível entre as partes intervenientes. Nesta medida, é um assunto da retórica. (É deste ponto de vista fundamental que devemos reler a distinção entre os dois conceitos feita tanto por Perelman como por Toulmin ao longo de décadas [cf. Perelman 1979, 117-123; Toulmin 1990, pp. 198-201]; e cujo papel, finalmente, é basicamente heurístico, quer dizer, visa apenas, como defendemos noutro lado [cf. Ribeiro 2015a] constituir um ponto de partida para que, finalmente, se venha a reformular cada um desses conceitos, e sobretudo o de "racional".) Mas, como vimos mais acima, esta conclusão fundamental já tinha sido tirada, a seu modo, pela própria filosofia de Quine e pela filosofia analítica de modo geral. Em que é que consiste, pois, a originalidade própria da abordagem retórica da ciência ?

A resposta consiste basicamente em dizer que, se é verdade que não existe um dado puro, virgem ou imune em relação às nossas interpretações, e, portanto, que as indeterminações da tradução e da referência de Relatividade Ontológica e outros Ensaios fazem todo o sentido, não devemos, por causa disso, despedir a filosofia, e que é sempre possível um discurso - a retórica- sobre a forma como nós falamos e argumentamos a respeito do mundo. 
É nesse discurso - um discurso sobre os discursos - que consiste, como já mostrámos mais acima, o futuro da filosofia. Ele pode dizer-nos alguma coisa sobre a natureza de maneira geral, mesmo que tal aconteça essencialmente sob o modo da inferência, e é, em consequência, a única metafísica possível e ao nosso alcance. Por exemplo, como sugerem Perelman \& Olbrechts-Tyteca (1958/2008, pp. 67 e ss.), a ideia - tão cara ao positivismo - de objetividade, pode ser reinterpretada como uma figura retórica do acordo estabelecido entre os cientistas (ou de uma dada comunidade científica) sobre a referência de uma dada teoria. Kuhn (1962/2012, pp. 66 e ss.) acrescentará: "à luz deste ou daquele paradigma". O pressuposto é que, onde existe conflito de interpretações, não há evidentemente padrão para decidir qual é a objetividade. O convencionalismo em matéria de filosofia da ciência, de Poincaré ao positivismo lógico e a Carnap em particular, já tinha defendido algo aparentemente similar, pondo o acento sobre as noções de acordo e de convenção (cf. Carnap 1966/1973), com a diferença fundamental de que, com ele, se continuava a pensar que essa referência existia efetivamente por si mesma e independentemente da sua interpretação através deste ou daquele sistema axiomáticodedutivo, e de que, por outro lado, as convenções em questão não possuíam significação retórica. Numa perspetiva como a de Quine (1953/1994, 1969), como vimos mais acima, uma tal referência será uma ficção, mas uma ficção que não se justifica investigar retoricamente.

É deste ponto de vista que se deve compreender a própria natureza retórica da noção contemporânea, própria do positivismo lógico, de sistema axiomático-dedutivo. Carnap (1975), como se sabe, tinha defendido que a escolha dos axiomas desses sistemas é essencialmente uma matéria da lógica; e que a aplicação empírica dos axiomas em questão passava pela sua interpretação ao abrigo deste ou daquele tipo de regras. Como vimos mais acima, Quine, em "Dois dogmas do empirismo", veio mostrar a irrelevância de toda essa conceção, e das noções de "analiticidade" e de "verificacionismo" em particular. Perelman (1989, pp. 109 e ss.) lê a crítica de Quine à luz das suas próprias perspetivas holistas em matéria de ciência. Se a objetividade e a referência são um mito, e a lógica é finalmente incapaz de justificar a escolha dos axiomas, então as razões que nos levam a fazê-la é um assunto da retórica. Passa, como já se disse, por um acordo entre os cientistas envolvidos, que se baseia, por sua vez, em premissas filosóficas mais gerais que dizem respeito à teoria em causa num dado domínio científico. Variando essas premissas, ou variando a teoria, varia naturalmente a própria objetividade ou referência. Kuhn (1962/2012), independentemente de Perelman e da retórica de maneira geral, amplia e aprofunda a ideia a que acabámos de aludir e o holismo que lhe está subjacente. Não se trata simplesmente de "cientistas" mas de comunidades científicas, porque desacordos podem existir - quanto 
a essa teoria -entre vários grupos ou comunidades, particularmente quando um dado paradigma ou programa de investigação mais geral entra em crise e outros se apresentam como alternativas para resolver os problemas que estão na origem da referida teoria (Kuhn 1962/2012, pp. 111 e ss.). Neste caso, o papel da retórica é muito mais importante e significativo, porque a eleição e escolha final de um paradigma triunfante passa essencialmente por ela, isto é, pela tarefa de persuasão da pertinência e vantagens desse paradigma em confronto com outros.

\section{Conclusão}

O que é feito da filosofia da ciência numa perspetiva como aquela que temos vindo a apresentar? Desde logo, a ideia moderna de que a filosofia possa fundar a ciência, e de que haja um certo tipo de conhecimento - o científico, e mais precisamente o da matemática e da física - que, por sua vez, sirva de paradigma ao conhecimento de maneira geral, deixa de fazer sentido. Foi essa, como se sabe, a grande bandeira da modernidade a partir de Descartes e de Kant. Já se disse: numa perspetiva como a da retórica, não há síntese a priori, não há conhecimento que seja universal e necessário nos termos da Crítica da Razão Pura; todo ele releva, de uma forma ou de outra, do âmbito do razoável, i. é, da retórica. É uma conclusão revolucionária e perturbadora, mas é a única que podemos tirar hoje em dia. (Deixemos aos físicos e à filosofia da ciência tradicional a ilusão que consiste em pensar que um tal conhecimento continua a ser possível; isso não nos deve preocupar.) Deste ponto de vista, a retórica é uma conceção essencialmente pós-moderna. Mas não compartilha com a pós-modernidade o ceticismo e relativismo a respeito da ideia de fundações universais para o conhecimento e a ação humana, porque ela própria pretende vir a fornecê-las de algum modo (que ainda está, de facto, por esclarecer), reconfigurando, em novos termos, completamente a árvore de Descartes em os Princípios da Filosofia. A interdisciplinaridade entre os vários campos do conhecimento, à luz da retórica ou, mais precisamente, da teoria da argumentação, é, como mostrámos noutros lados (Ribeiro 2012a, 2012b), uma das vias fundamentais para o efeito. Ela passa por se vir a encontrar, como aspirava Toulmin $(1958,1976)$ e Perelman \& Olbrechts-Tyteca $(1952,1958 / 2008)$ igualmente sugeriam, um modelo de argumentação e, em especial, conceitos sistemáticos comuns a todos esses campos (como foi o caso, com esses autores, dos de "racional" e "razoável"). Mais geralmente, trata-se de repensar à luz da retórica, filosoficamente compreendida, as fundações metafísicas possíveis para a argumentação de modo geral, como Toulmin $(1976,2001)$ intentou e, mais particularmente, Haber- 
mas (1981-1984, 1981-1987) procurou fazer (cf. Ribeiro 2012b). Tudo isto - dada a novidade e originalidade envolvidas naquilo a que chamámos "viragem retórica" - é trabalho em progresso e essencialmente por desenvolver.

\section{REFERÊNCIAS}

Bochenski, J. M. (1961). A History of Formal Logic. Notre Dame, Ind.: University of Notre Dame Press.

Carnap. R. (1966/1973). Les fondements philosophiques de la logique. Trad. J.-M Luccioni \& A. Soulez. Paris: Armand Colin.

Carnap, R. (1975). Meaning and Necessity: A Study on Semantics and Modal Logic. Chicago/London: Press The University of Chicago.

Cassirer, E. (1907). Cassirer und die modern Mathematik. Kant-Studien, 12: 1-49.

Coffa, A. (1995). The Semantic Tradition from Kant to Carnap: To the Vienna Station. Ed. L. Wessels. Cambridge: Cambridge University Press.

Copi, I., \& Cohen, C. (1953/1994). Introduction to Logic. 9th edition. New York, NY: Macmillan Publishing Company.

Descartes, R. (1644/1985). The Philosophical Writings of Descartes (Vol 1). Transl. by J. Gottingham, R. Stoothoff and D. Murdoch. Cambridge: Cambridge University Press.

Feyerabend, P. (1987). Farewell to Reason. London: Verso/Newleft Books.

Feyerabend, P. (1999). Knowledge, Science and Relativism: Philosophical Papers (Vol. 3). Ed. by J. Preston. Cambridge: Cambridge University Press.

Friedman, M. (1992). Philosophy and the exact Sciences: Logical positivism as a case study. In J. Earman (Ed.), Inference, Explanation, and Other Frustrations: Essays in the Philosophy of Science (pp. 84-98). Berkeley/Los Angeles/Oxford: University of California Press.

Friedman, M. (1999). Reconsidering Logical Positivism. Cambridge: Cambridge University Press.

Friedman, M., \& Nordmann, A. (Eds.) (2006). The Kantian Legacy in the Nineteenth-Century Science. Cambridge: MIT Press.

Habermas, J. (1981/1984). Theory of Communicative Action. Volume One: Reason and the Rationalization of Society. Transl. T. A. McCarthy. Boston, MA: Beacon Press.

Habermas, J. (1981/1987). Theory of Communicative Action. Volume Two: Liveworld and System: A Critique of Functionalist Reason. Trans. T. A. McCarthy. Boston, MA: Beacon Press.

Hegel, G. W. F. (1812/1972). Science de la logique. Premier tome, Premier livre: L'être. Trad. P.-J. Labarrière \& G. Jarczyk. Paris: Aubier-Montaigne.

Kant, I. (1787/1985). Crítica da Razão Pura. Trad. A. Morujão e M. P. dos Santos. Lisboa: Ed. C. Gukbenkian. 
Kuhn, T. S. (1962/2012). The Structure of Scientific Revolutions (With an Introductory Essay by I. Hacking). Chicago, IL: Chicago University Press.

Lyotard, J.-F. (1979), La condition postmoderne. Rapport sur le savoir. Paris: Éditions de Minuit.

Nagel, E. (1961/1974). A Estructura da Ciência. Trad. G. Klimovski. Buenos Aires: Paidos.

Nauser, G. A. (Ed.) (2007). Philosophy and Rhetoric in Dialogue: Redrawing their Intellectual Ladscape. Pennsylvania: The Pennsylvania State University Press.

Perelman, Ch. (1979). The New Rhetoric and the Humanities: Essays on Rhetoric and its Applications. Dordrecht: Kluwer Academic Publishers.

Perelman, Ch. (1989). Rhétoriques. Bruxelles: Editions de Université de Bruxelles.

Perelman, Ch., \& Olbrechts-Tyteca, L. (1952). Rhétorique et philosophie: pour une théorie de l'argumentation en philosophie. Paris: PUF.

Perelman, Ch., \& Olbrechts-Tyteca, L. (1958/2008). The New Rhetoric: A Treatise on Argumentation. Transl. by J. Wilkinson and P. Weaver. Notre Dame/London: University of Notre Dame Press.

Popper, K. R. (1959/1974). The Logic of Scientific Discovery. 7th impression. London: Hutchinson of London.

Popper, K. R. (1963/1991). Conjectures and Refutations: The Growth of Scientific Knowledge. 5th ed. (revised). London: Routledge \& Kegan Paul.

Popper, K. R. (1976). Unended Quest: An Intellectual Autobiography. La Salle (IL): Open Court Publishing.

Popper, K. R. (1994). The Myth of the Framework: In Defense of Science and Rationality. Ed. M. A. Notturno. London/New York: Routledge.

Quine, W. van. O. (1953/1994). From a Logical Point of View: Logico-Philosophical Essays. Cambridge, MA/London : Harvard University Press.

Quine, W. van O. (1962). Le mythe de la signification. In J. Wahl et al. (Eds.), La philosophie analytique (pp. 138-169). Paris: Les Editions de Minuit.

Quine, W. van O. (1969). Ontological Relativity and Other Essays. New York, NY: Columbia University Press.

Quine, W. van O. (1975). The nature of natural knowledge. In S. Gutennplan (Ed.), Mind and Language (pp. 67-81). Oxford: Clarendon Press.

Quine, W. van O. (1995). From Stimulus to Science. Cambridge, MA/London: Harvard University Press.

Ribeiro, H. J. (1998). O fim da filosofia da ciência na história da filosofia analítica. Revista Portuguesa de Filosofia, 54(3-4): 395-428.

Ribeiro, H. J. (2004). Rejeição vs. aceitação de Kant na filosofia analítica contemporânea. Revista Filosófica de Coimbra, 26: 393-409.

Ribeiro, H. J. (2005). Kant, os começos da filosofia analítica e o 'Wiener Kreis'. Revista Portuguesa de Filosofia, 61(3-4): 883-899.

Ribeiro, H. J. (2007). Kant e o positivismo lógico vienense: O manifesto do "Círculo de Viena" como caso em estudo. In L. R. dos Santos et al. (Eds.), Kant: Posteri- 
dade e Actualidade (Colóquio Internacional) (pp. 589-599). Lisboa: Centro de Filosofia da Universidade de Lisboa.

Ribeiro, H. J. (2009). Perelman and Toulmin as philosophers: On the inalienable connection between philosophy, rhetoric and argumentation. In H. J. Ribeiro (Ed.), Rhetoric and Argumentation in the Beginning of the XXIst Century (pp. 33-51). Coimbra: Coimbra University Press.

Ribeiro, H. J. (2012a). Editor's Introduction. The birth of argumentation theory in the 20th Century: A quiet revolution. In H. J. Ribeiro (Ed.), Inside Arguments: Logic and the Study of Argumentation (pp. 1-21). Newcastle upon Tyne: Cambridge Scholars Publishing.

Ribeiro, H. J. (2012b). On the divorce between philosophy and argumentation theory. Revista Filosófica de Coimbra, 42: 479-498.

Ribeiro, H. J. (2012c). Rhétorique et philosophie: Perelman et la philosophie analytique. In B. Frydman \& M. Meyer (Dir.), Chaïm Perelman (1912-2012): De la nouvelle rhétorique à la logique juridique (pp. 161-185). Paris: Presses Universitaires de France.

Ribeiro, H. J. (2012d). What about argumentation in Wittgenstein's philosophy ? On Stephen Toulmin's connections. In M. G. Weiss \& H. Greif (Eds.), Ethics-Society-Politics. Papers of the 35th Wittgenstein International Symposium (August 5-11, 2012) (pp. 132-134). Kirchberg am Wechsel (Austria): Austrian Ludwig Wittgenstein Society.

Ribeiro, H. J. (2013a). Estudos sobre a filosofia na Europa e em Portugal: De Antero de Quental a Leonardo Coimbra. Coimbra: MinervaCoimbra.

Ribeiro, H. J. (2013b). What argumentation (theory) can do for philosophy in the 21 st century. In D. Mohammed \& M. Lewinski (Eds.), Virtues of Argumentation. Proceedings of the 10th International Conference of the Ontario Society for the Study of Argumentation (OSSA), 22-26 May 2013 (pp. 1-8). Windsor, ON: OSSA.

Ribeiro, H. J. (2013c). Returning to the relations between logic and argumentation and other classic issues. Argumentation: An International Journal on Reasoning, 27: 459-463.

Ribeiro, H. J. (2015a). In the face of relativism: Stephen Toulmin's latest views on rhetoric and argumentation. Revista Filosófica de Coimbra, 47: 95-109.

Ribeiro, Henrique Jales (2015b). Karl Popper's influence on contemporary argumentation theory. In B. Garssen \& F. Snoeck-Henkemans (Eds.) (2015), Proceedings of the 8th Conference of the International Society for the Study of Argumentation (University of Amsterdam, July 2-4, 2014). Amsterdam: ISSA (in the press).

Rorty, R. (1967/1992). The Linguistic Turn: Essays in Philosophical Method with Two Retrospective Essays. Chicago and London: The University of Chicago Press. 
Rorty, R. (1979). Philosophy and the Mirror of Nature. Princeton, NJ: Princeton University Press.

Rorty, R. (1991). Objectivity, Relativism, and Truth. Philosophical Papers (Vol. 1). Cambridge: Cambridge University Press.

Russell, B. (1903/1992). The Principles of Mathematics. London: Routledge.

Simons, H. W. (Ed.) (1990). The Rhetorical Turn: Invention and Persuasion in the Conduct of Inquiry. Chicago, IL: The University of Chicago Press.

Toulmin, S. (1958). The Uses of Argument. Cambridge: Cambridge University Press.

Toulmin, S. (1976). Knowing and Acting: An Invitation to Philosophy. New York: Macmillan Publishing Co.; London: Collier Macmillan Publishers.

Toulmin, S. (1990). Cosmopolis: The Hidden Agenda of Modernity. Chicago, IL: The University of Chicago Press.

Toulmin, S. (2001). Return to Reason. Cambridge, MA/London: Harvard University Press.

Wittgenstein, L. (1921/1933). Tractatus Logico-Philosophicus with an Introduction by Bertrand Russell. London: Kegan Paul.

Wittgenstein, L. (1953). Philosophical Investigations. Ed. by G. E. M. Anscombe and R. Rhees. Transl. by G.E.M. Anscombe. Oxford: Blackwell. 